\title{
Research on Cognitive Load Theory: Application to E-Learning
}

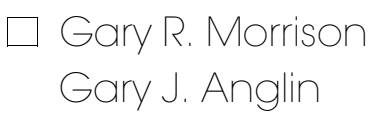

The purpose of this article is to review and critique each of the research studies published in this special issue. We will critique each article, derive one or more instructional design heuristics based on the findings for each study, and provide recommendations for extending particular lines of research. Three suggestions are provided concerning cognitive load theory and instructional design adaptations for e-learning.
The design and development of e-learning materials presents the instructional designer with an environment, opportunities, and constraints quite different from those associated with the design of instruction for a traditional classroom context. In the traditional, face-to-face classroom, instructional designers tend to rely on the instructor or the students' peers to make needed adaptations and support if a student fails to understand an idea. A student who fails to understand a lesson typically has immediate access to the instructor or other students to ask questions or to test their understanding. In an elearning environment, a student may start a lesson at 2:00 a.m. and e-mail an instructor at 2:45 a.m. asking for help with understanding a concept. Lacking an available instructor or peer, the student may stop studying in frustration, or worse, develop a misconception.

The design of e-learning instruction and the actual learning take place in two different time frames. That is, the instructor first designs the instruction and then, a month or more later, the student uses the instructional materials to learn the content. This separation of design and actual learning requires the learner to reintegrate the teaching and learning process (Keegan, 1996), often, in the absence of the instructor. This reintegration process places a significant responsibility on the learner for developing an understanding without the direct and immediate support of the instructor and peers. To address this problem, Holmberg (1989) suggested that designers develop a guided didactic conversation or internal speech the student has with the instructor as the student processes the instructional materials.

If the instructional designer creates instructional materials that impose too much extrane- 
ous load, then the student will not develop an understanding of the course content. The articles in this special issue of Educational Technology Research and Development (ETRED) address three general categories of strategies designers can use to address the design of e-learning materials. Proper management of cognitive load through sound instructional design principles are an essential component for the design of efficient and effective e-learning materials that lead to an understanding of the content by the individual learner who has the option of learning 24/7.

Our goal in this article is to provide a summary of the main articles in the special issue, identify design heuristics that instructional designers can apply to the design of e-learning materials, and provide suggestions for future research. We wish to caution the reader that these heuristics are based on the studies presented in this special issue rather than on multiple studies. The heuristics should be used with caution until they are validated with additional research.

\section{TRACEY CLARKE, PAUL AYRES, AND JOHN SWELLER}

In many cases it is assumed that using technology will enhance learning efficacy by improving both the efficiency and effectiveness of the learning experience. In e-learning environments, students are expected to learn how to use delivery technology such as Blackboard and WebCt, including skills such as chatting online, participating in threaded discussions, and posting assignments. In many cases learning about the delivery technology takes place concurrently with the learning of content and accomplishment of primary content goals. At the lesson level, students may be expected to use technology and software as part of a content learning experience (strategy). Clarke, Ayres, and Sweller, informed by cognitive load theory, examined the impact of the timing of learning technology skills (spreadsheet skills) when learning mathematical concepts. Two sequencing strategies, (a) learning spreadsheet skills and then mathematical concepts in sequence, and (b) learning spreadsheet skills and mathematics concepts concurrently were included. A subjective measure of cognitive load was also administered.

\section{Heuristic}

We present one heuristic based on the Clarke et al. study that could be considered when designing e-learning materials. The reader should be cautioned that our heuristic is based on the results of one study, with a relatively low sample size, that focused on learning mathematical concepts. The primary finding is compatible with the expectation of an expertise reversal effect (Kalyuga, Ayres, Chandler, \& Sweller, 2003). We will state our heuristic in general terms, knowing that additional research needs to be conducted to confirm our initial generalization.

1. A strategy requiring initial learning of technology skills, then particular content area concepts, will enhance learning for students with a low level of technology skills.

For students with a low level of technology knowledge and skill, the technology content most likely has high element interactivity. Intrinsic cognitive load may be increased if technology skills and specific subject content area concepts are learned concurrently. The learner's level of technology skills, and the level of content element interactivity are critical variables when determining the sequencing strategy (Kalyuga et al., 2003; van Merriënboer, Kirschner, \& Kester, 2003).

\section{Future Research Recommendations}

Jeroen J. G. van Merriënboer and Paul Ayres, in their introduction to this special issue of ETRED, suggest that early research informed by cognitive load theory focused on the use of instructional methods to reduce extraneous cognitive load, whereas more recent research concerns the impact of instructional methods on germane and intrinsic cognitive load given the prior knowledge level of learners. In the Clarke et al. study it is reported that students with low prerequisite knowledge of spreadsheets learned mathematics concepts more efficiently if the 
spreadsheet skills were learned prior to learning the mathematics content. However for more experienced spreadsheet users, Clarke et al. did not report significantly different performance on mathematics learning test scores for students receiving spreadsheet and mathematics content instruction concurrently. Future research on sequencing strategies (sequential and concurrent), including technology and mathematics content with high element interactivity, is needed. It would also be appropriate to examine if the effects found by Clarke et al. can be replicated with other content areas such as history and knowledge domains. If the results of such replication studies were similar to the results reported by Clarke et al. there would be more general support for the expertise reversal effect across content disciplines.

Given relative low sample size, 9 students in the sequential group and 11 students in the concurrent group, statistical power may be lacking in the analysis. Additional studies with larger sample sizes would help to further determine effectiveness of sequential and concurrent sequencing strategies. Clarke et al. used selfassessment reports to "measure" cognitive load and spreadsheet skills. Although self-assessment is a useful research tool, we recommend for future research that cognitive load and spreadsheet skills be directly assessed or measured. Finally, future studies extending the work of Clarke et al. should be conducted with students actually enrolled in e-learning courses. This approach would improve the ecological validity of future investigations.

FRED PAAS, JUHANI E. TUOVINEN, JEROEN J. G. VAN MERRIËNBOER, AND A. AUBTEEN DARABI

Studies with external validity are of particular interest to the instructional designer (Ross \& Morrison, 1989). Typically, these studies use realistic materials and employ realistic environments as opposed to the highly controlled environments of a basic research study. Extending basic research findings with applied research through the use of realistic materials and environments provides valid insights as to how our instructional designs will be used in a realistic setting (Ross \& Morrison, 2004). Paas, Tuovinen, van Merriënboer, and Darabi have taken a similar approach in their research that introduces motivation as a variable for optimizing instructional materials. They suggest that motivation may be a critical factor in the design of instructional materials that engage the learner and enhance the learner's effort. Of particular interest in their research is the effect of realistic materials on learner motivation in contrast to the effort and motivation observed in studies with high internal validity that may use contrived or artificial materials.

Paas et al.'s calculation of task involvement provides an interesting approach to a new research area. What effect does learner motivation have on task involvement (i.e., task performance)? Designers are constantly faced with finding an optimum balance between easy and difficult materials that will challenge the learner while trying to avoid frustration or materials so easy that the learner's effort results in only meager gains. Paas et al.'s task-involvement concept provides some insight into how designers might adapt materials to individual learner needs.

\section{Heuristics}

We have identified two heuristics from this article that are applicable to an e-learning environment. The first is based on a trend in the data rather than on significant findings and should be used with caution until future research can validate the heuristic.

1. Exploratory practice results in greater involvement than do worked examples for experienced students.

Problem-based learning (PBL) and worked examples provide two contrasting approaches to instructional design. PBL can provide a rich, realistic context that allows the learner to explore various options, whereas worked examples provide a guided approach. Both approaches have been validated (Albanese \& Mitchell, 1993; Dochy, Segers, Van den Bossche, \& Gijbels, 2003; Paas \& Van Merriënboer, 1994; Sweller \& Cooper, 1985). This heuristic suggests that students with no prior knowledge might benefit first from worked examples, then move 
to a PBL environment to increase their involvement and mental effort.

2. Students with no prior knowledge will have less efficiency with exploration practice than with worked examples.

Although an exploratory or open-ended learning environment might provide more engagement for all learners, the efficiency of such practice may be an issue when there is limited time for the training. If an exploratory strategy is needed or more appropriate, students with no prior knowledge might first start with worked examples before using the exploratory examples.

\section{Future Research Recommendations}

We agree with Paas et al. that future research considering cognitive load theory and motivation should focus on realistic environments. Similarly, future research should attempt to replicate and validate many of the research findings in realistic settings to provide instructional designers with more robust information. Another recommendation is for the development of unobtrusive measures of motivation and cognitive load that instructional designers can use to adapt e-learning materials during the instruction. Last, we suggest that future studies examine the effect of cognitive load on motivation in a variety of conditions that affect motivation.

\section{ROXANA MORENO AND FRED VALDEZ}

It is clear that learners are required to process many external representations during their elearning experiences. Investigations examining the impact of multiple representations on learning and cognitive processing are warranted (Anglin, Vaez, \& Cunningham, 2004). Incorporating Mayer and Moreno's (2003) cognitive theory of multimedia learning (CTML), Moreno and Valdez examined the effect of interactivity and feedback when learning from either single (words) or multiple (words and pictures) external representations in the area of meteorology. Retention and problem solving were assessed and cognitive load was measured using a subjective measure.

Heuristics

We present two tentative design heuristics based on the results from the Moreno and Valdez investigation. The reader is reminded that more research is needed in order to confirm that out heuristics apply across various content areas.

1. Presenting two integrated nonredundant external representations (verbal and visual) in contrast to one (verbal or visual) will result in higher student performance levels and require less mental effort by learners.

The findings reported by Moreno and Valdez in Experiment 1 support the claim that two external representations (visual, verbal) facilitate student learning better than either of the single external representations, visual or verbal. Similar effects were identified for both cognitive load and learning efficiency. There are many kinds of interactivity and feedback. Our heuristic is developed assuming that designers would use the specific types of interactivity (organize causal chain of events) and feedback (frame-byframe) included in the Moreno and Valdez study.

2. Strategies for interactivity that involve the learner in the process of understanding (schema development) prior to feedback will enhance transfer learning.

In many technology-based instructional programs, information is presented to the learners and they are asked to view worked examples, construct an argument, or perform a critical evaluation. After the student response, feedback is given to learners concerning the quality of their response. The results of Experiment 3 in Moreno and Valdez provide evidence that this may not be the best strategy. It may be more appropriate to include interactivity that helps the students construct meaning and develop understanding relative to the instructional content before giving them feedback. 


\section{Future Research Recommendations}

The Moreno and Valdez study is based on Mayer and Moreno's (2003) CTML. The CTML incorporates three assumptions: (a) dual coding (Clark \& Paivio, 1991), (b) active processing (meaning construction), and (c) limited working memory. The results of the Moreno and Valdez study are consistent with CTML. Future studies could replicate and extend the studies by including content from disciplines other than science or mathematics, given that online learning experiences with technology are being designed and developed for many content areas. Investigation of the impact of additional interaction strategies that engage the student in the understanding and meaning-making process, as well as feedback timing, would also be appropriate.

The Moreno and Valdez study focused on the impact of two external representations on learning and working memory load in a multimedia environment. There are a myriad of external representations presented to students in e-learning materials, verbal and visual. We are not convinced that many of the external representations included in e-learning materials promote effective cognitive processes for learning. As with the early research conducted to determine the effects of pictures and illustrations on learning, we think a framework that considers the functions that multiple external representations serve in learning materials would be useful to researchers (Anglin et al., 2004). Ainsworth (1999) has provided a taxonomy that could be invaluable to researchers attempting to determine the effectiveness of multirepresentational learning contexts. Ainsworth presented three major functions, and additional subfunctions, of multiple external representations in instructional materials: (a) complimentary roles, (b) constrain interpretation, and (c) construct deeper understanding. It is clear that students do have trouble translating across multiple representations. The translation process is assumed to increase working memory load, as for example in the split attention effect (Sweller, van Merriënboer, \& Paas, 1998). Translation problems can occur when the learner is translating across verbal representations only, visual representations only, or both. Studies that consider how multiple representations function and studies that attempt to identify effective translation processes required by the learner across functions are needed. Such research would help identify "how translations across representations should be supported to maximize learning outcomes" (Ainsworth, p. 132).

\section{WOLFGANG SCHNOTZ AND THORSTEN RASCH}

Results of studies examining the effect of animations on learning have been mixed. When designing e-learning materials, it is important for the instructional designer to make sound and informed decisions concerning the inclusion of animations in e-learning materials for optimal student learning and understanding. Schnotz and Rasch investigated the effect of two types of animations on knowledge acquisition. The investigators identified two functions of animations, enabling and facilitating, that are assumed to reduce cognitive load. Schnotz and Rasch also distinguished between learners with high and low learning prerequisites. They did not directly measure cognitive load. We have identified one heuristic in this study; however, a number of the effects identified by Schnotz and Rasch were reported as marginally significant. Therefore, the reader is cautioned that more research needs to be conducted to confirm or deny our heuristics.

\section{Heuristic}

1. For learners with high learning prerequisites, inclusion of animated pictures that can be manipulated will enhance learning and allow for cognitive processing that would otherwise not be possible.

The results reported by Schnotz and Rasch based on their 2-experiment study provide evidence for the claim that different types of animations perform different functions in the learning process. Animations (manipulation) designed to enable cognitive processing were effective for learners with high learning prerequisites. Schnotz and Rasch also reported that animations (simulation) designed to reduce cognitive 
load for tasks that would otherwise require additional mental effort by the learner did function in a facilitative way but did not enhance learning.

\section{Future Research Recommendations}

We support the functional approach taken by Schnotz and Rasch. Based on their findings it appears that learning prerequisites and animation functions are critical variables to consider when incorporating animations into instructional materials. It appears that learners with high and low learning prerequisites will benefit from strategies incorporating animations designed to serve different functions. We recommend additional research to further confirm the relationship between animation function, learning prerequisites, and germane cognitive load. As we discussed in our critique of the Moreno and Valdez study, the study of multiple external representations in multimedia learning environments is a complex task. The identification of the functions that external representations serve is critical. We believe that consideration of cognitive load theory and Ainsworth's (1999) taxonomy of multiple external representations would be very useful to researchers interested in examining the effect of animations on student learning and understanding in an e-learning environment.

\section{ERIK WALLEN, JAN L. PLASS, AND ROLAND BRÜNKEN}

Managing cognitive load is a critical issue when designing e-learning. If the combination of intrinsic and extraneous load is too great, the learner will not develop an understanding of the instructional content as intended. The individualized nature and separation of the learner from other learners and the instructor in e-learning places a greater responsibility for developing an understanding on the individual learner than in the traditional face-to-face classroom. The article by Wallen, Plass, and Brünken investigated the use of text annotations to support the develop- ment of schemas. Three strategies, using (a) selection, (b) organization, and (c) integration were tested individually and in pairs to determine their effectiveness for enhancing learning.

Heuristics

We have identified three heuristics from the study that are relevant to the design of e-learning materials. Readers are cautioned that these heuristics are based on a single study that uses relatively small group sizes for the analysis; thus, statistical power may be lacking in the analysis.

1. Adding verbal annotations to text can improve recall and transfer performance.

Providing learners with definitions of terms with contextual information (selection level), brief explanations of an idea in the specific context (organization level), or by showing links of ideas in a paragraph (integration level) can enhance recall of terms and ideas. Integrating one of these strategies does not appear to increase extraneous cognitive load significantly, but rather, it may enhance germane cognitive load. This strategy is potentially useful as a means of providing additional instructional support for the e-learning student.

2. Selection and organization-level annotations can enhance comprehension.

When the recall of idea units rather than words is the goal, learner performance is enhanced with the use of selection and organization-level annotations. Thus, providing definitions and explanations as an adjunct to the text can enhance recall of idea units.

3. Providing more than one type of annotation results in a decrease in performance.

When using annotations to enhance learning, increasing the types of annotation results in a degrading effect. That is, using both selection and organization-level annotation results in a lower performance than using only selection or organization-level annotation. The additional annotation increases the amount of text a learner must process and may result in an increase in extraneous cognitive load. This increase in cognitive load may exceed the learner's capacity 
and result in the failure to develop an adequate schema for the material.

\section{Future Research Recommendations}

The Wallen et al. study presents an interesting line of research that extends cognitive load research beyond a message design focus. Focusing on how instructional strategies affect cognitive load is an area that should be of interest to instructional designers of not only e-learning, but of all mediated forms of instruction. Based on the Wallen et al. article, we have identified five areas of future research:

1. The present study used annotations as an adjunct that required the learner to use a mouse action to view the annotation. Future studies should investigate the effectiveness and effect on cognitive load of embedding the annotations in the text versus presenting them as an adjunct.

2. Wittrock's (1974a; 1974b) generative learning theory provides a better conceptual framework for future studies than Levin, Anglin, and Carney's (1987) picture functions. Jonassen (1988) identified four informationprocessing strategies-(a) recall, (b) integration, (c) organizing, and (d) elaboration - that are consistent with Wittrock's generative learning theory and provide a basis for learning strategies used with textual information.

3. Future studies should compare the active learning strategies identified by Jonassen to the passive annotations used by Wallen et al. to determine if there are differences in performance and cognitive load. Although the more active strategies may increase extraneous cognitive load, they tend to promote germane cognitive load by helping the learner construct new ideas (Grabowski, 2004).

4. Future studies investigating the effect of instructional strategies on cognitive load should measure cognitive load rather than suggesting that such strategies result in an increase. Of particular interest is determining the effects on extraneous and germane cognitive load and how these strategies interact with the two. Similarly, future studies should also investigate the effect of verbal ability and expertise.

5. Robust measures of performance should be used that focus on comprehension and higher levels of learning through application rather than on recall of ideas or idea units. Providing data using realistic measures of performance will help instructional designers determine the appropriateness and viability of the strategy for implementation in a real-world application.

\section{TAMARA VAN GOG, K. ANDERS ERICSSON, REMY M. J. P. RIKERS, AND FRED PAAS}

Van Gog, Ericsson, Rikers, and Paas raise several interesting issues related to the design of instructional materials for advanced learners. Identification of the expertise reversal effect (Kalyuga et al., 2003) suggests that designers should use caution when creating designs to manage extraneous cognitive load for learners who have developed expertise in an area. Concluding that different instructional designs are required for learners of different level of expertise may be premature according to van Gog et al. Additional research is needed to understand how the different instructional designs affect learners of different abilities. For example in elearning, a simple adaptive system might make one design effective for different learners. Kalyuga et al. described a study that incorporated an electrical diagram and an electrical diagram with integrated text, with experienced learners doing better with the diagram only and inexperienced learners doing better with the diagram and text. A simple adaptive computerbased system could use either program or learner control to turn the embedded text elaborations off or on in the display.

A second design issue raised by van Gog et al. addressed deliberate practice and motivation . Designers are faced with developing appropriate practice that challenges and motivates the learner without overloading the learner. Prior research by Ross and his associates (Ross, 1984; Ross \& Rakow, 1982) and Tennyson and his associates (Tennyson \& Buttery, 1980) have 
investigated both learner and program control strategies for deliberate practice. Van Gog et al's suggestions are consistent with prior research that we need to help students learn to make appropriate choices regarding practice as they develop expertise.

\section{Heuristics}

There are two heuristics in the van Gog et al. article relevant to e-learning.

1. Designing deliberate practice strategies to enhance germane cognitive load can lead to the development of expertise.

Mindful design of learner-appropriate, deliberate practice that includes feedback to encourage learners to reflect on their errors may enhance germane cognitive load. Strategies can incorporate reflection, and other elaboration strategies can enhance learning from errors.

\section{The effectiveness of deliberate practice is enhanced if the learner is motivated.}

Learners must not only be motivated to engage in the practice, they must also be engaged in a mindful way so that they can make effective use of the feedback to correct errors and develop appropriate schemas. Research on feedback has found that learners who are motivated in a realistic setting will make more mindful use of feedback than students who are simply participating in an experiment (Morrison, Ross, Gopalakrishnan, \& Casey, 1995). Instructional designers need to devise an instructional strategy that is not only engaging, but is also motivating.

\section{Future Research Recommendations}

Van Gog et al. have identified a number of areas for future research when using cognitive load theory with advanced learners. We have identified five related areas of research that would extend the current cognitive load theory research and be of benefit to those designing elearning:

1. Further investigate the expertise reversal effect to determine the extent of the effect when designing materials for different levels of learner expertise. For example, are integrated text and diagrams effective for advanced learners when the content is at an advanced level?

2. Develop a systematic research plan to determine if instructional designs elicit the same responses from learners with varying levels of expertise. Van Gog et al. propose that instructional design theory has assumed strategies that elicit the same response from all learners.

3. Investigate the structure of schemas, and determine how experts use those schemas to solve problems.

4. Extend schema research to determine feasibility of supplanting an expert's schema.

5. Determine the effectiveness and efficiency for a naïve learner to develop an appropriate schema.

\section{SLAVA KALYUGA AND JOHN SWELLER}

The use of adaptive models using various algorithms and approaches has a rich history of research in the field of instructional technology (Ross, 1984; Ross \& Rakow, 1982; Tennyson \& Buttery, 1980; Tennyson \& Rothen, 1979). Kalyuga and Sweller have extended this research by using cognitive load as an adapting variable. By using a rapid measure of semantic knowledge and a subjective cognitive load measure, they calculated cognitive efficiency to adapt instruction to each learner. Combining these two measures allows the designer to adapt the instruction for the next step as well as the level of difficulty. Although the study was an initial exploration, the results are encouraging for future research using this approach for adapting instruction.

\section{Heuristic}

We have identified one heuristic from this study; however, designers are cautioned that it is based on only one study and additional research is needed. It does provide a unique 
approach to adapting instruction that could provide a more efficient approach to individualization.

1. Making adaptive decisions based on performance and a subjective measure of cognitive load may result in more efficient learning.

This heuristic provides an alternative to designing one form of instruction and relying on time as the individualization factor. To implement this approach, designers would need to have instruction written for at least two levels of difficulty and implement a rapid assessment approach. The participants in the study were 10th-grade students who participated in frequent testing as part of the learning process. Adults who are not as accustomed to frequent testing may not be as successful or willing to learn using this approach.

\section{Future Research Recommendations}

We offer three suggestions for future research to further develop this approach to adapting instruction in an e-learning environment:

1. Studies should be conducted in other knowledge domains. The current study was conducted with math problems that are highly structured and have high element interactivity. Future studies should consider less-structure areas such as interpersonal and management skills, where researchers might vary the complexity and difficulty of cases or examples to teach a concept or rule. Similarly, future research might consider the effectiveness of the system when using a problem-based learning approach to develop problem solving and analysis skills.

2. Future studies should consider the effectiveness of adapting instruction based on performance as well as performance + cognitive load measures. Is there adequate benefit for adding the cognitive load variable to the equation as well as the time needed to collect the data? Can we assume that if a student failed to master a step, the instruction was too difficult and an alternative format is needed?

3. There is a need for a new measure of cognitive load, especially one that is objective.
Kalyuga and Sweller indicated that a less intrusive measure is needed in an e-learning environment. This measure would be useful for not only adaptive instructional research, but also other cognitive load studies.

Studies such as Kalyuga and Sweller's, that extend cognitive load research beyond message design into the area of instructional strategy design, provide an important and interesting approach to the design of instruction. Bruner, Goodnow and Austin (1956) suggested that we, as designers, should consider the cognitive strain our designs imposed on the learner, but we have only recently had a framework for considering this strain with cognitive load theory.

\section{SUMMARY}

Early research based on cognitive load theory attempted to identify methods of reducing extraneous cognitive load (Sweller et al., 1998). In this article we have critiqued seven studies that have expanded information on issues concerning intrinsic cognitive load, germane cognitive load, and perquisite skills. We have presented some tentative design heuristics based on the results of the studies that we reviewed, along with suggestions for future research. More research needs to be completed to provide a sound research base for our heuristics.

Considering all of the studies we critiqued, we can draw several conclusions. There is a plethora of e-learning courses available in various knowledge domains. Future research should include knowledge domains such as social studies, geography, and psychology, as well as skill areas such as interpersonal communication. We also recommend that future studies incorporate objective measures of cognitive load. Much progress has been made with student rating scales, but objective measures would add an additional level of measurement precision. The development of unobtrusive measures of cognitive load would facilitate the work of both researchers and designers concerned with e-learning environments. If designers are to incorporate cognitive load as an adaptive vari- 
able in e-learning, a less obtrusive measure is needed. More research is needed on cognitive load theory and effective instructional design strategies, conducted with realistic settings. Students may or may not be motivated by the same reasons they are in a controlled laboratory setting. Thus, researchers should consider conducting applied studies that sacrifice some internal validity at the expense of higher external validity.

These studies will provide new information regarding the application of these and other heuristics. Based on the findings of studies published in this special issue of ETRED, we also conclude that the relation of perquisite learning and cognitive load is a critical research area. It appears that strategies appropriate for learners with low learning perquisites may not be optimal for learners with high learning perquisites, considering the impact of such strategies on extraneous, germane, and intrinsic cognitive load. Instructional messages presented in e-learning environments include many external representations (i.e., visual and verbal representations). In future research studies, we recommend that investigators use a classification system to identify the particular function each external representation is assumed to serve. It would then be easier to isolate the impact of multiple external representations on learning and working memory load. Last, we recommend that a study of the impact on working memory of various interactive strategies such as paraphrasing and summarizing, be conducted.

Gary R. Morrison [GMorriso@odu.edu] is a professor in the Educational Curriculum and Instruction Department at Old Dominion University.

Gary J. Anglin is an associate professor in the Department of Curriculum and Instruction at the University of Kentucky.

Correspondence concerning this article should be addressed to Gary R. Morrison, Educational Curriculum and Instruction, Education 145, Old Dominion University, Norfolk, VA 23529.

\section{REFERENCES}

Ainsworth, S. (1999). The functions of multiple representations. Computers and Education, 33, 131-152.

Albanese, M. A., \& Mitchell, S. (1993). Problem-based learning: A review of the literature on its outcomes and implementation issues. Academic Medicine, 68, 52-81.

Anglin, G. J., Vaez, H., \& Cunningham, K. L. (2004). Visual representations and learning: The role of static and animated graphics. In D. H. Jonassen (Ed.), Handbook of research for educational communications and technology (2nd ed., pp. 865-916): Mahwah, NJ, Lawrence Erlbaum Associates, Publishers.

Bruner, J. S., Goodnow, J. J., \& Austin, G. A. (1956). A study of thinking. New York: Wiley.

Clark, J. M., \& Paivio, A. (1991). Dual coding theory and education. Educational Psychology Review, 3, 149210.

Dochy, F., Segers, M., Van den Bossche, P., \& Gijbels, D. (2003). Effects of Problem-Based Learning: A Meta-Analysis. Learning and Instruction, 13(5), 533568.

Grabowski, B. J. (2004). Generative learning contributions to the design of instruction and learning. In D. J. Jonassen (Ed.), Handbook of educational communications and technology (2nd ed., pp. 719-743). Hillsdale, NJ: Lawrence Erlbaum Associates, Publishers.

Holmberg, B. (1989). Theory and practice of distance education. New York: Routledge.

Jonassen, D. J. (1988). Integrating learning strategies into courseware to facilitate deeper process. In D. J. Jonassen (Ed.), Instructional designs for microcomputer courseware (pp. 151-181). Hillsdale, NJ: Lawrence Erlbaum Associates, Publishers.

Kalyuga, S., Ayres, P., Chandler, P., \& Sweller, J. (2003). Expertise reversal effect. Educational Psychologist, 38, 23-31.

Keegan, D. (1996). Foundations of distance education (3rd ed.). London: Routledge.

Levin, J. R., Anglin, G. J., \& Carney, R. R. (1987). On empirically validating functions of pictures in prose. In D. M. Willows \& H. A. Houghton (Eds.), The psychology of illustration: Vol. I. Basic research (pp. 51-85). New York: Springer.

Mayer, R. E., \& Moreno, R. (2003). Nine ways to reduce cognitive load in multimedia learning. Educational Psychologist, 38, 43-52.

Morrison, G. R., Ross, S. M., Gopalakrishnan, M., \& Casey, J. (1995). The effects of feedback and incentives on achievement in computer-based instruction. Contemporary Educational Psychology, 20, 32-50.

Paas, F., \& van Merriënboer, J. J. G. (1994). Variability of worked examples and transfer of geometrical problem solving skills: A cognitive load approach. Journal of Educational Psychology, 86, 122-133.

Ross, S. M. (1984). Matching the lesson to the student: Alternative adaptive designs for individualized learning systems. Journal of Computer-Based Instruction, 11, 42-47.

Ross, S. M., \& Morrison, G. R. (1989). In search of a happy medium in instructional technology research: Issues concerning external validity, media replications, and learner control. Educational Technology Research and Development, 37(1), 19-33.

Ross, S. M., \& Morrison, G. R. (2004). Experimental 
Research Methods. In D. J. Jonassen (Ed.), Handbook of Research on Educational Communications and Technology (pp. 1021-1043). Mahwah, NJ: Lawrence Erlbaum Associates, Publishers.

Ross, S. M., \& Rakow, E. (1982). Adaptive instructional strategies for teaching rules in mathematics. Educational Communications and Technology Journal, 30, 6774.

Sweller, J., \& Cooper, G. (1985). The use of worked examples as a substitute for problem solving in algebra. Cognition and Instruction, 2, 59-89.

Sweller, J., van Merriënboer, J. J. G., \& Paas, F. (1998). Cognitive architecture and instructional design. Educational Psychology Review, 10, 251-296.

Tennyson, R. D., \& Buttery, T. (1980). Advisement and management strategies as design variables in com- puter-assisted instruction. Educational Communications and Technology Journal, 28, 169-176.

Tennyson, R. D., \& Rothen, W. (1979). Management of Computer-Based Instruction: Design of an Adaptive Control Strategy. Journal of Computer-Based Instruction, 5(3), 63-71.

van Merriënboer, J. J. G., Kirschner, P., \& Kester, L. (2003). Taking the load off a learner's mind: Instructional design for complex learning. Educational Psychologist, 38, 5-13.

Wittrock, M. C. (1974a). A generative model of mathematics education. Journal of Research in Mathematics Education, 5(4), 181-196.

Wittrock, M. C. (1974b). Learning as a generative process. Educational Psychologist, 19(2), 87-95. 